\title{
Contraception and conception in Mid-life: a review of the current literature
}

\author{
Kristin Van Heertum ${ }^{*}$ (D) and James Liu
}

\begin{abstract}
In the United States, there are an increasing number of couples who are intentionally delaying child-bearing. As the average age of mothers continues to rise, more and more women are being faced with the difficulties of attempting conception at the various stages leading up to the menopausal transition. Not only do the chances of conception drastically decrease after the age of 40 years, but the probability of fetal loss (both early and late in pregnancy) significantly increases during this period as well. The aims of this review include providing an overview of the natural progression of the menopausal transition, examining the importance of appropriate contraception, and identifying the difficulties that women face when attempting conception during this physiologically dynamic stage of life. Finally, we will discuss the non-contraceptive benefits of contraception in preparation for pregnancy during the mid-life.
\end{abstract}

Keywords: Mid-life, Mid-life contraception, Mid-life fertility, Perimenopause, Menopausal transition

\section{Background}

Over the past several decades, the mean age of mothers in the United States has continued to increase $[1,2]$. The mean maternal age at first birth in 1970 was 21.4 years, which increased to 24.9 years in 2000 and 26.3 years in 2014. This pattern was documented to occur across all birth orders. The birth rate for women age 40-44 years has continued to increase over the last 3 decades (Fig. 1). For example, in 2015, the birth rate in this age group was 11 births per 1,000 women, up 4\% from the year prior [3]. More strikingly, the number of births in the U.S. occurring in women who are $\geq 45$ years rose from 0.3 births per 1,000 women in the early 1990's to 0.8 births per 1,000 women in 2013 [4, 5]. As women continue to further delay childbearing, more couples may be affected by the natural fertility decline that occurs in the mid-life. In this review, we will discuss the physiological decline in ovarian reserve and the resulting decrease in fecundity and fecundability, as well as the need for contraception during this phase; the risks of pregnancy with advancing maternal age; and the options for fertility treatment and family planning in this age group.

\footnotetext{
* Correspondence: kristin.vanheertum@uhhospitals.org University Hospitals MacDonald Women's Hospital, 11100 Euclid Avenue, Cleveland, $\mathrm{OH}$ 44106, USA

\section{Physiology of menopause}

Menopause is defined as the absence of menses for one year due to the depletion of ovarian reserve [6]. The median age of natural menopause in the United States is 51.4 years [7]. Prior to the final menstrual period, there are a variety of hormonal changes that occur in relation to the dwindling number of functional ovarian follicles. The earliest hormonal change in the menopausal transition is the gradual decrease in serum inhibin B levels $[8,9]$. This is followed by a gradual increase in serum FSH levels and ultimately a subsequent decrease in circulating estradiol levels.

The Daily Hormone Study (DHS), a part of the Study of Women's Health Across the Nation (SWAN), examined daily urine collections for up to 50 days annually for 3 years in 848 women aged $43-53$ years [10]. The aim of this study was to document declining luteal function through the menopausal transition by measuring urinary $\mathrm{LH}, \mathrm{FSH}$, and metabolites of both estrogen and progesterone. There was a significant decrease in the number of ovulatory cycles documented over the 3-year study period $(80.9 \% \rightarrow 64.7 \%)$; additionally, there was an increased number of anovulatory cycles with no bleeding, which was associated with progression to early perimenopause $(\mathrm{OR}=2.66)$ or late perimenopause $(\mathrm{OR}=56.21)$. The number of anovulatory cycles that were associated 


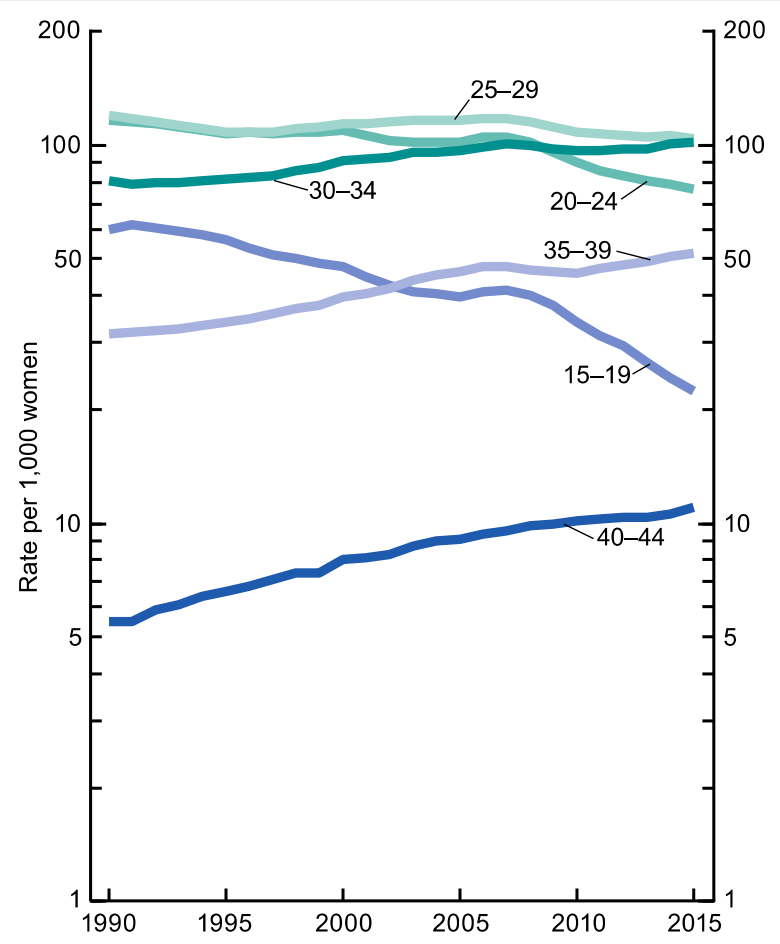

Fig. 1 Birth rates, by age of mother: United States, 1990-2015. Reproduced from [3] (public domain). NOTE: Rates are plotted on a logarithmic scale. SOURCE: NCHS, National Vital Statistics System

with a bleeding episode did not change over the course of the study (approximately 10\%) and were not associated with progression to perimenopause. However, pregnanediol glucuronide, a surrogate measure for serum progesterone levels, decreased by $6.6 \%$ each year. Thus, the study documented a decrease in luteal progesterone, albeit small, even in ovulatory cycles as well as a decrease in the proportion of ovulatory cycles across the progression through the menopausal transition. In addition, the study demonstrated that anovulatory cycles without a bleed were relatively hypoestrogenic compared with anovulatory cycles associated with a bleeding episode. The study also found that both low and high early follicular-phase estradiol were predictive of progression in the menopausal transition. The proposed decrease in ovulatory cycle progesterone production may contribute to the decreased fecundability that has been well-documented in this age group. It has been hypothesized that this progressive deficiency in the luteal phase is a result of impaired folliculogenesis [11]. As inhibin B decreases, FSH not only increases overall, but starts to increase earlier in the luteal phase of the preceding cycle [12-14]. This leads to earlier follicular recruitment, a shortened follicular phase and abnormal folliculogenesis, that leads to a defective luteal phase.

These functional shifts in the pattern of folliculogenesis result in alterations of the length of menstrual cycles. As women age, they may experience either shortening or lengthening of their cycles due to a shortened follicular phase, impaired folliculogenesis, and an increasing number of anovulatory cycles. The clinical correlates to these physiologic alterations are the hallmark symptoms of menopause: hot flushes (hypothalamic response to decreased estrogen levels), sleep disturbances (often associated with hot flushes), and depressed mood $[6,15]$.

\section{Fecundability in the Mid-life}

Evaluation of fecundity, defined as the fertility potential, can be assessed by highly sensitive urine hCG testing. In a study of married women not using contraception in rural Bangladesh tested for the presence of urinary hCG twice weekly, the probability of conceiving in a single menstrual cycle began to significantly decline in the early 40's [16]. However, the fecundity rate, the probability of achieving live birth in a single menstrual cycle, is further decreased by an increasing rate of fetal loss with increasing maternal age. A study from the Danish Health Service was able further stratify the increasing risk of fetal loss with maternal age. Anderson et al. 2000 queried fetal loss data from the civil registration system in Denmark from 1978 to 1992 [17]. The study documented a miscarriage risk of $8.9 \%$ at ages $20-24$ years, $54.5 \%$ at age 42 years, and $74.7 \%$ in women aged 45 years or older (Fig. 2). The risk of fetal loss significantly increased after age 35 years, with a risk of greater than $20 \%$ at age 35 years. The incidence of stillbirth was also found to rise after age 35 years (Fig. 3).

\section{Prevention of unintended pregnancy}

Despite the decreasing fecundity that comes with increasing age, women in the midlife still need reliable contraception. Currently, the American College of Obstetricians and Gynecologists recommends continuation of contraception

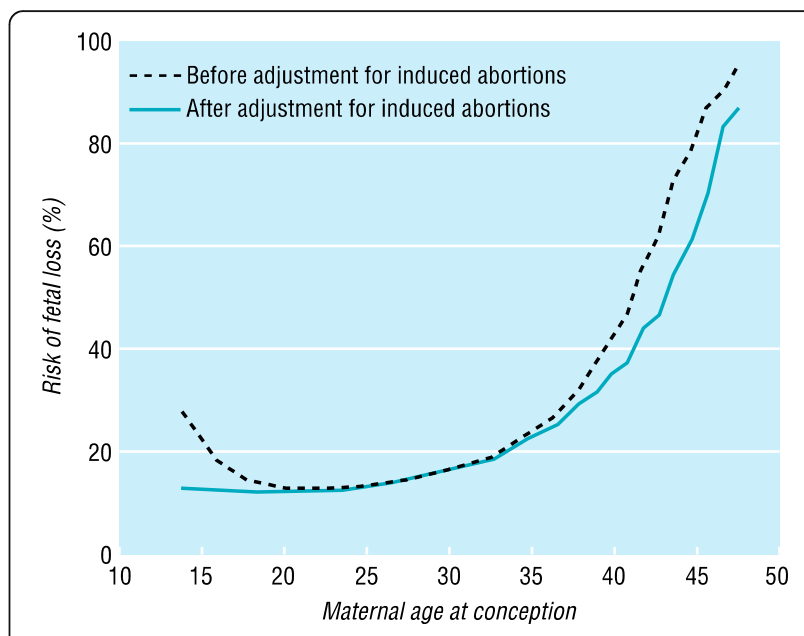

Fig. 2 Risk of fetal loss by maternal age at conception. Reproduced with permission from [17] 


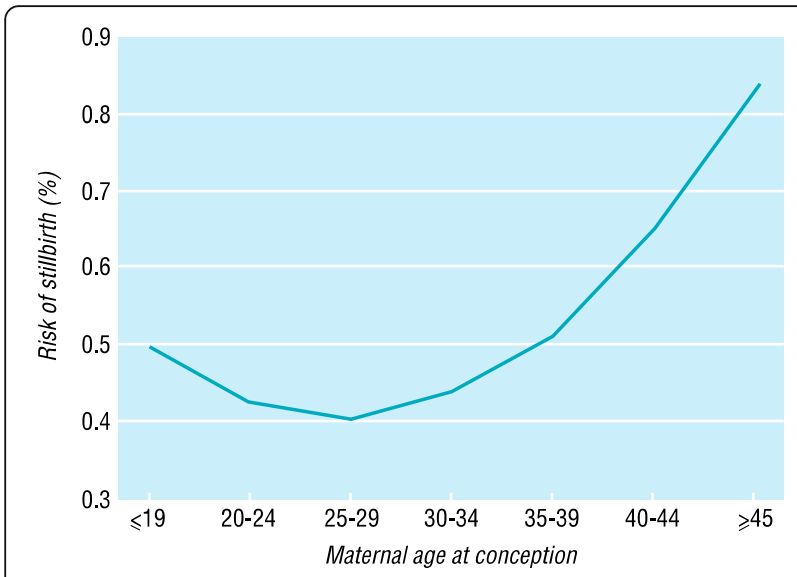

Fig. 3 Risk of stillbirth by maternal age. Reproduced with permission from [17]

until 50-55 years of age in those women who wish to prevent pregnancy [18]. In 2006, the overall rate of unintended pregnancy in the United States was $49 \%$, with $48 \%$ of those being in women age 40-44 years [19]. It is difficult to estimate how many women in this age group are at risk for unintended pregnancy. However, one study from Europe examining data from five different countries estimated that approximately $30 \%$ of women ages $45-49$ years were not using any form of contraception [20]. Another study, which used data from the Massachusetts Behavioral Risk Factor Surveillance System, found that $14.7 \%$ of women ages $40-44$ years and $16.8 \%$ of women ages $45-50$ years who were at risk for unintended pregnancy were not using any form of contraception [21].

Unintended pregnancy is of particular concern when women are suffering from comorbid conditions that would not only result in significant health risk if they were to become pregnant, but could even result in death. Such conditions include hypertension, diabetes and heart disease, which have an increasing prevalence with advancing age [22]. While the overall maternal mortality rate in the U.S. has continued to increase over the years, the most substantial increase has been noted in women age 45 and older. In 1993 there were no reported deaths from 2,329 live births in the U.S. in this age group, while in 2014 there were 171 maternal deaths reported in 8,443 live births [23].

There is also a higher risk of pregnancy-specific complications with advancing age. Women over the age of 44 have a greater risk of gestational diabetes, cesarean delivery, pregnancy-related hypertensive disorders and fetal aneuploidy [24]. Generally, any form of contraception is felt to be safe for women age 45 years and older, provided that they do not have other risk factors [22]. However, as women age, the incidence of comorbidities such as hyperlipidemia, hypertension, heart disease, stroke, venous thromboembolism, and diabetes, increases.
These conditions can preclude the use of estrogencontaining forms of contraception, however other forms of contraception are considered safe alternatives in these patients, including intrauterine devices (IUDs) and progestin-only implants.

\section{Noncontraceptive benefits of contraceptives}

Hormonal contraceptives offer a variety of benefits beyond pregnancy prevention. Any form of hormonal contraception, including combined oral contraceptives $(\mathrm{COCs})$ and progestin-only contraceptives (progestin-only pill, injection, implant or IUD) decreases the amount of menstrual blood loss experienced by women and can be used as a temporizing agent in women suffering from heavy menses [25]. This can be a useful approach in patients who wish to avoid surgery, particularly to maintain their fertility potential. Additional benefits of hormonal contraceptives include reductions in both endometrial and ovarian cancer risk. Both COCs and depot medroxyprogesterone acetate have been found to significantly reduce the risk of endometrial cancer. This effect may last for up to 20 years following cessation of treatment [26-29]. The levonorgestrel intrauterine system can provide local progestin action with minimal systemic effects. This type of IUD is an effective treatment for endometrial hyperplasia without atypia, and will decrease endometrial cancer risk [30, 31]. A meta-analysis of data from 45 epidemiologic studies of women with ovarian cancer versus controls showed a reduction in ovarian cancer risk of $27 \%$ with the use of COCs [32].

Another condition that is frequently treated with hormonal contraceptives is endometriosis. The reported incidence of endometriosis varies depending on the study population; however, approximately $10 \%$ of reproductive age women will have endometriosis [33]. This incidence is higher in those presenting with pain or infertility. Conversely, $30-50 \%$ of women with endometriosis with have sub- or infertility [34]. The efficacy of in vitro fertilization (IVF) appears to be decreased in patients with endometriosis. A 2002 meta-analysis of studies comparing IVF outcomes in women with endometriosis versus tubal factor showed a significantly lower pregnancy rate in patients with endometriosis (odds ratio 0.56; $95 \%$ confidence interval 0.44-0.7), with even lower pregnancy rates in women with severe endometriosis compared to those with mild disease (odds ratio 0.6 ; $95 \%$ confidence interval 0.42-0.87) [35]. Women with endometriosis are often treated with COCs or progestin-only therapy to suppress their disease and provide pain relief. These medical suppressive therapies, however, prevent ovulation and conception.

A Cochrane review examined randomized trials comparing GnRH agonist, danazol and COCs with placebo in patients with a diagnosis of endometriosis. The study found no difference in spontaneous pregnancy rates 
with any treatment versus placebo [36]. The American Society of Reproductive Medicine (ASRM) does not recommend delaying infertility treatment with medical suppression of endometriosis as there is no improvement in pregnancy rates [37]. On the other hand, another Cochrane review showed that pre-treatment with prolonged $\mathrm{GnRH}$ agonist therapy may improve IVF outcomes [38].

\section{Planning for conception in mid-life}

Women who wish to discontinue contraception and attempt to conceive may experience a variable length of time to resumption of normal menses. Barnhart et al. examined the time to pregnancy after discontinuation of a continuous regimen of levonorgestrel $90 \mu \mathrm{g}$ and ethinyl estradiol $20 \mu \mathrm{g}$ [39]. The study found pregnancy rates of $57 \%, 81 \%$, and $86 \%$ at 3,12 and 13 months, respectively, suggesting there is no significant delay in the return to fertility with continuous OC regimens. However, these women were all 35 years or younger. Therefore, this information may not be generalizable to the population in question in this review.

\section{Third-party reproduction}

The likelihood of a successful live birth in older women, particularly over the age of 45, is low. Even with IVF, the oocyte yield and quality will be poor in patients over the age of 42 [40]. Donor oocyte remains a reliable way to significantly increase the chance of live birth in women at advancing ages, though even this does not provide a $100 \%$ chance of success. Current studies show that with donor oocytes, older women have success rates similar to the age of the oocyte donor [41]. Alternatively, many women may be without a male partner for various reasons. Donor intrauterine inseminations could be a viable option in these patients.

\section{Conclusions}

The negative effect of age on reproductive potential is well known. As women approach menopause, it is important that they continue to use reliable contraception to reduce the risk of unintended pregnancy. Once patients are ready to conceive, they need to receive adequate pre-conception counseling regarding their risks in pregnancy, risk of fetal loss, and raising a child at an older age. Women of advancing age often suffer from infertility, so there should be no delay in referring them to a fertility specialist. These women may require more aggressive therapies such as superovulation, IVF or donor oocyte and/or sperm.

\section{Abbreviations}

ASRM: American Society of Reproductive Medicine; COC: Combined oral contraceptives; DHS: Daily hormone study; FSH: Follicle-stimulating hormone; IUD: Intrauterine device; IVF: In vitro fertilization; LH: Luteinizing hormone; SWAN: Study of Women's Health Across the Nation
Acknowledgements

Not applicable.

Funding

Not applicable.

Availability of data and materials

Not applicable.

Authors' contributions

$\mathrm{KV}$ and $J \mathrm{~L}$ collaborated to write this article together. All authors read and approved the final manuscript.

\section{Authors' information}

Kristin Van Heertum is a clinical instructor of Obstetrics and Gynecology at the Case Western Reserve University School of Medicine Department of Reproductive Biology. James Liu is the Chair of Obstetrics and Gynecology at University Hospitals Cleveland Medical Center and Professor of Reproductive Biology at Case Western Reserve University. He is a practicing Reproductive Endocrinologist and is on the Executive Board of the North American Menopause Society.

Ethics approval and consent to participate

Not applicable.

Consent for publication

Not applicable.

Competing interests

Kristin Van Heertum has no conflicts to disclose. James Liu is a consultant for Allergans, Sermonix, Ferring Pharmaceuticals, and Charter Venture Capital.

\section{Publisher's Note}

Springer Nature remains neutral with regard to jurisdictional claims in published maps and institutional affiliations.

Received: 13 February 2017 Accepted: 12 July 2017

Published online: 16 August 2017

References

1. Mathews TJ, Hamilton BE. Mean age of mother, 1970-2000. Natl Vital Stat Rep. 2002;51(1):1-14

2. Mathews TJ, Hamilton BE. Mean age of mothers is on the rise: United States, 2000-2014. NCHS Data Brief. 2016;232:1-8.

3. Martin JA, Hamilton BE, Osterman MJK, Driscoll AK, Mathews TJ. Births: final data for 2015. Natl Vital Stat Rep. 2017;66(1):1-70.

4. Martin JA, Hamilton BE, Osterman MJ, Curtin SC, Mathews TJ. Births: final data for 2012. Natl Vital Stat Rep. 2013:63:1-68.

5. Hamilton BE, Martin JA, Osterman MJK, Curtin SC. Births: preliminary data for 2013. Natl Vital Stat Rep. 2014;63(2):1-19.

6. Lobo RA. Menopause and aging. In: Strauss JF, Barbieri RL, editors. Yen and Jaffe's reproductive endocrinology. 7th ed. Philadelphia, PA: Elsevier Saunders; 2014. p. 308-39.

7. Gold EB, Bromberger J, Crawford S, Samuels S, Greendale GA, Harlow SD, Skurnick J. Factors associated with age at natural menopause in a multiethnic sample of midlife women. Am J Epidemiol. 2001;153(9):865-74.

8. Sherman BM, Korenman SG. The menopausal transition: analysis of LH, FSH, estradiol and progesterone concentrations during menstrual cycles of older women. J Clin Endocrinol Metab. 1976;42:629-36.

9. Santoro N, Crawford SL, Lasley WL, Luborsky JL, Matthew KA, McConnell D, Randolph Jr JF, Gold EB, Greendale GA, Korenman SG, Powell L, Sowers MF, Weiss $\mathrm{G}$. Factors related to declining luteal function in women during the menopausal transition. J Clin Endocrinol Metab. 2008;93(5):1711-21.

10. Burger HG, Dudley EC, Robertson DM, Dennerstein L. Hormonal changes in the menopause transition. Recent Prog Horm Res. 2002;57:257-75.

11. Sherman BM, Korenman SG. Measurement of serum LH, FSH, estradiol and progesterone in disorders of the human menstrual cycle: the inadequate luteal phase. J Clin Endocrinol Metab. 1974:39:145-9.

12. Lee SJ, Lenton EA, Sexton L, Cooke ID. The effect of age on the cyclical patterns of plasma LH, FSH, oestradiol and progesterone in women with regular menstrual cycles. Hum Reprod. 1988;3(7):851-5. 
13. Klein NA, Illingworth PJ, Groome NP, McNeilly AS, Battaglia DE, Soules MR. Decreased inhibin $B$ secretion is associated with the monotropic rise in FSH in older, ovulatory women: a study of serum and follicular fluid levels of dimeric inhibin A and B in spontaneous cycles. J Clin Endocrinol Metab. 1996;81:2742-5.

14. Santoro N, Isaac B, Neal-Perry G, Adel T, Weingart L, Nussbaum A, Thakur S, Jinnai $H$, Khosla N, Barad D. Impaired folliculogenesis and ovulation in older reproductive aged women. J Clin Endocrinol Metab. 2003;88:5502-9.

15. Ditkoff EC, Crary WG, Cristo M, Lobo RA. Estrogen improves psychological function in asymptomatic postmenopausal women. Obstet Gynecol. 1991;78:991-5.

16. O'Connor KA, Holman DJ, Wood JW. Declining fecundity and ovarian ageing in natural fertility populations. Maturitas. 1998;30:127-36.

17. Anderson AN, Wohlfahrt J, Christens P, Olsen J, Mads M. Maternal age and fetal loss: population based register linkage. BMJ. 2000;320:1708-12.

18. American College of Obstetrician Gynecologists. Guidelines for Women's health care: a resource manual: part 3: patient care. Washington (DC): The College; 2007

19. Finer LB, Zolna MR. Unintended pregnancy in the United States: incidence and disparities, 2006. Contraception. 2011;84(5):478-85.

20. Skouby SO. Contraceptive use and behavior in the $21^{\text {st }}$ century: a comprehensive study across five European countries. Eur J Contracept Reprod Health Care. 2010;15 suppl 2:S42-53.

21. Godfrey EM, Zapata LB, Cox CM, et al. Unintended pregnancy risk and contraceptive use among women 45-50 years old: Massachusetts, 2006, 2008, and 2010. AJOG. 2016;214:712.e1-8.

22. Centers for Disease Control and Prevention. US medical eligibility criteria for contraceptive use. MMWR Recomm Rep. 2016;65(3):1-108.

23. Joseph KS, Lisonkova S, Muraca GM, Razaz N, Sabr Y, Mehrabadi A, Schisterman E. Factors underlying the temporal increase in maternal mortality in the United States. Obstet Gynecol. 2017;129(1):91-100.

24. Schoen C, Rosen T. Maternal and perinatal risks for women over 44: a review. Mauritas. 2009;64:109-13.

25. Noncontraceptive uses of hormonal contraceptives. Practice bulletin No. 110 American College of obstetrician gynecologists. Obstet Gynecol. 2010;115:206-18.

26. Centers for Disease Control. Oral contraceptive use and the risk of endometrial cancer. JAMA. 1983;249:1600-4.

27. Schlesselman JJ. Risk of endometrial cancer in relation to use of combined oral contraceptives. A practitioner's guide to meta-analysis. Hum Reprod. 1997:12:1851-63.

28. Depo-medroxyprogesterone acetate (DMPA) and risk of endometrial cance. The WHO collaborate study of neoplasia and steroid contraceptives. Int J Cancer. 1991;49:186-90.

29. Kaunitz AM. Depo medroxyprogesterone acetate contraception and the risk of breast and gynecologic cancer. J Reprod Med. 1996;41:419-27.

30. Buttini MJ, Jordan SJ, Webb PM. The effect of the levonorgestrel releasing intrauterine system on endometrial hyperplasia: an Australian study and systematic review. Aust N Z J Obstet Gynaecol. 2009;49:316-22.

31. Soini T, Hurskainen R, Grenman S, Maepaa J, Paavonen J, Pukkala E. Cancer risk in women using the levonorgestrel-releasing intrauterine system in Finland. Obstet Gynecol. 2014;124(2 Pt 1):292-9.

32. Collaborate Group on Epidemiological Studies of Ovarian Cancer. Ovarian cancer and oral contraceptives: collaborative reanalysis of data from 45 epidemiological studies including 23,257 women with ovarian cancer and 87,303 controls. Lancet. 2008;371:303-14.

33. Giudice LC, Kao LC. Endometriosis. Lancet. 2004;364(9447):1789-99.

34. Harkki P, Tiitinen A, Ylikorkala O. Endometriosis and assisted reproductive techniques. Ann N Y Acad Sci. 2010;1205:207-13.

35. Barnhart K, Dunsmoor-Su R, Coutifaris C. Effects of endometriosis on in vitro fertilization. Fertil Steril. 2002;77(6):1148-55.

36. Hughes E, Brown J, Collins JJ, Farquhar C, Fedorkow DM, Vandekerckhove P. Ovulation suppression for endometriosis. Cochrane Database Syst Rev. 2007; 3:CD000155.

37. Endometriosis and infertility. a committee opinion. Fertil Steril. 2012;98:591-8.

38. Sallam HN, Garcia-Velasco JA, Dias S, Arici A. Longterm pituitary downregulation before in vitro fertilization (IVF) for women with endometriosis. Cochrane Database Syst Rev. 2006;25:CD004635.
39. Barnhart K, Mirkin S, Grubb G, Constantine G. Return to fertility after cessation of a continuous oral contraceptive. Fertil Steril. 2009;91(5):1654-6.

40. Gleicher N, Kushnir VA, Albertini DF, Barad DH. Improvements in IVF in women of advanced age. J Endocrinol. 2016;230:F1-6.

41. Wang YA, Farquhar C, Sullivan EA. Donor age is a major determinant of success in oocyte donation/recipient programme. Hum Reprod. 2012;27(1):118-25.

\section{Submit your next manuscript to BioMed Central and we will help you at every step:}

- We accept pre-submission inquiries

- Our selector tool helps you to find the most relevant journal

- We provide round the clock customer support

- Convenient online submission

- Thorough peer review

- Inclusion in PubMed and all major indexing services

- Maximum visibility for your research

Submit your manuscript at www.biomedcentral.com/submit
C Biomed Central 